\title{
The Application of Virtual Manufacturing Technology in the Course Reform of Manufacturing Technology
}

\author{
$\mathrm{Li} \mathrm{WANG}^{1, a,{ }^{*}}$ and En-guang ZHANG ${ }^{2, b}$ \\ ${ }^{1,2}$ Department of mechanical and automotive engineering, Zhuhai College of Jilin \\ University, Zhuhai, China \\ awangli00019@163.com, bteamcenter@163.com
}

\begin{abstract}
Keywords: Virtual manufacturing, Fundamentals of manufacturing technology, Course reform, Cutting tool, Jig.
\end{abstract}

\begin{abstract}
According to the fact that manufacturing industry is developing to virtualization, digital, green and intelligent, this paper proposed an innovation course reform of the fundamentals of manufacturing technology, that is to apply the virtual manufacturing $(\mathrm{VM})$ technology to the theory teaching process. The specific application occasions are illustrated in this paper. Practice has proved that this reform can better achieve the teaching purpose of the course, which has certain significance.
\end{abstract}

\section{Introduction}

The fundamental of manufacturing technology is a basic course for the students majoring in mechanical engineering, which is strongly comprehensive and closely contact with production practice [1]. Its purpose is to cultivate the students to master the basic knowledge of machining, and enable the students to have the basic skills of process design and fixture design. It not only serves for the study of subsequent professional courses, but also can be used directly in production practice [1].

$\mathrm{VM}$ is the essence of the actual manufacturing process on computer, which uses computer simulation and virtual reality technology to collaborate in computer group to achieve the nature of products' manufacturing such as product design, process planning, manufacturing, performance analysis, quality inspection, and management and control at all levels of the enterprise, in order to enhance decision and control ability of the manufacturing process at all levels. It is using the computer virtual model to simulate and predict the product function, performance and machinability and other possible problems [2] in order to optimize the product design quality and manufacturing process, optimize production management and resource planning, thus to improve the forecast and decision level. It makes the development of manufacturing technology to a new stage of comprehensive forecast. It is the highest level of CAD/CAE/CAM integration. It fundamentally changed the past technical model of manual drawing and organizing the whole production process according to drawings [3]. It can improve the work efficiency of machine design and manufacture, and also improve the quality of the whole design [4].

In Zhuhai College of Jilin University, there are more than 500 students per year studying the course of fundamentals of manufacturing technology. Applying the VM technology in the course reform of manufacturing can make teaching visualization and automation higher. It gets good teaching effect. 


\section{Course Offered}

One of the key teaching features in mechanical design, manufacturing and automation major of our college is to combine the advanced VM software with the traditional theory course. We set the VM software courses such as CAD/CAE/CAM throughout the entire four years of college education, and the instruction is given step by step. The fundamental of manufacturing technology course is set in the junior year. At this time, applying the VM software can make the students feel kind. It also can make the students more clearly about the purpose of learning VM software. At the same time, it improves the students' sense of achievement and interesting in this course [5].

There are some examples to illustrate the application of VM technology in the teaching reform of the basic theory of manufacturing technology.

\section{Application in the Teaching Reform of Tool Marking Angles}

The cutting tool is the most direct instrument for manufacturing. To remove the material from the work piece, the cutting tool must have a certain cutting angle. Tool marking angles are important angles of tool manufacture, grinding and measurement. So it is one of the most important knowledge of manufacturing technology course. However, it is necessary to introduce the orthogonal plane reference system to mark the cutting tool angles. It is very difficult for students to understand this knowledge because the three mutually perpendicular reference planes are abstract and invisible. This often requires making teaching aids in traditional teaching methods. But there are a lot of drawbacks. For one thing, making teaching aids is often time-consuming, laborious and high cost because of the wide variety of cutting tools and their different structures. For another, the effective display scope of teaching aids in the classroom teaching process is limited. However, CAD technology can be used to build a variety of 3D tool models fast and conveniently. It can also show the orthogonal plane reference system visually. The interactive interface of CAD software allows students to rotate the viewing angle of the tool freely. The projector makes every student even in the last row of the classroom can clearly see every mark angle of the cutting tool, which reflects again the role of VM technology in the traditional theory teaching. Figure 1 shows the 3D model of the lathe tool and its orthogonal plane reference system with CAD technology.

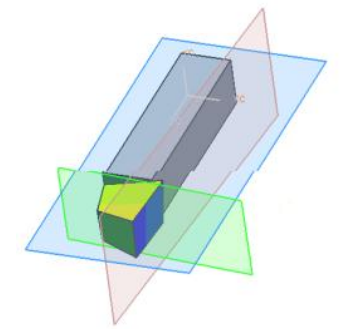

Figure 1 CAD model of the lathe tool and its orthogonal plane reference system

\section{Application in the Teaching Reform of Machine Tool Fixture Design}

As far as the parts manufacturing is concerned, the design of jigs, especially the special machine tool fixture, directly affects the quality and efficiency of a batch of parts. The design of special machine tool fixture is complex. It contains fixture, positioning device, clamping device, tool guide element, connecting element and other components etc. 
The feasibility and convenience of loading and unloading of work piece should be considered in the design process. Alignment of the positioning device, clamping device, tool guide element and connecting element with the fixture body, and the position relations among these elements should also be considered. The traditional fixture design method often requires rework because the physical design and the state of the process in actual implementation are of the contrary. This will extend the design cycle, delay the processing time of products, and even miss the best period of market competition. In traditional teaching process, making physical teaching aids is time-consuming and high cost. And because the machining fixtures needed by different parts and even different surfaces of the same part are not the same, it is difficult to completely make the physical teaching aids. So alone with the showing of text and pictures, the teaching effect is boring and it is obscure for students to understand. In addition, the manufacturing market has gradually evolved from the relative stability of the past to the dynamic characteristics, product updates faster and faster, and the market demands are already moving towards the direction of small batch and personalized [2]. All of these make the VM technology more and more popular, which is to use computer aided technology to design, process and assemble. It can facilitate the design of clamping scheme, shorten product development cycle, greatly reduce the clamping error, improve manufacturing accuracy and make the teaching effect more vivid and intuitive, which is easier for students to accept and understand. Take the fixture design of the drilling process of some sleeve part as an example, as shown in Figure 2.

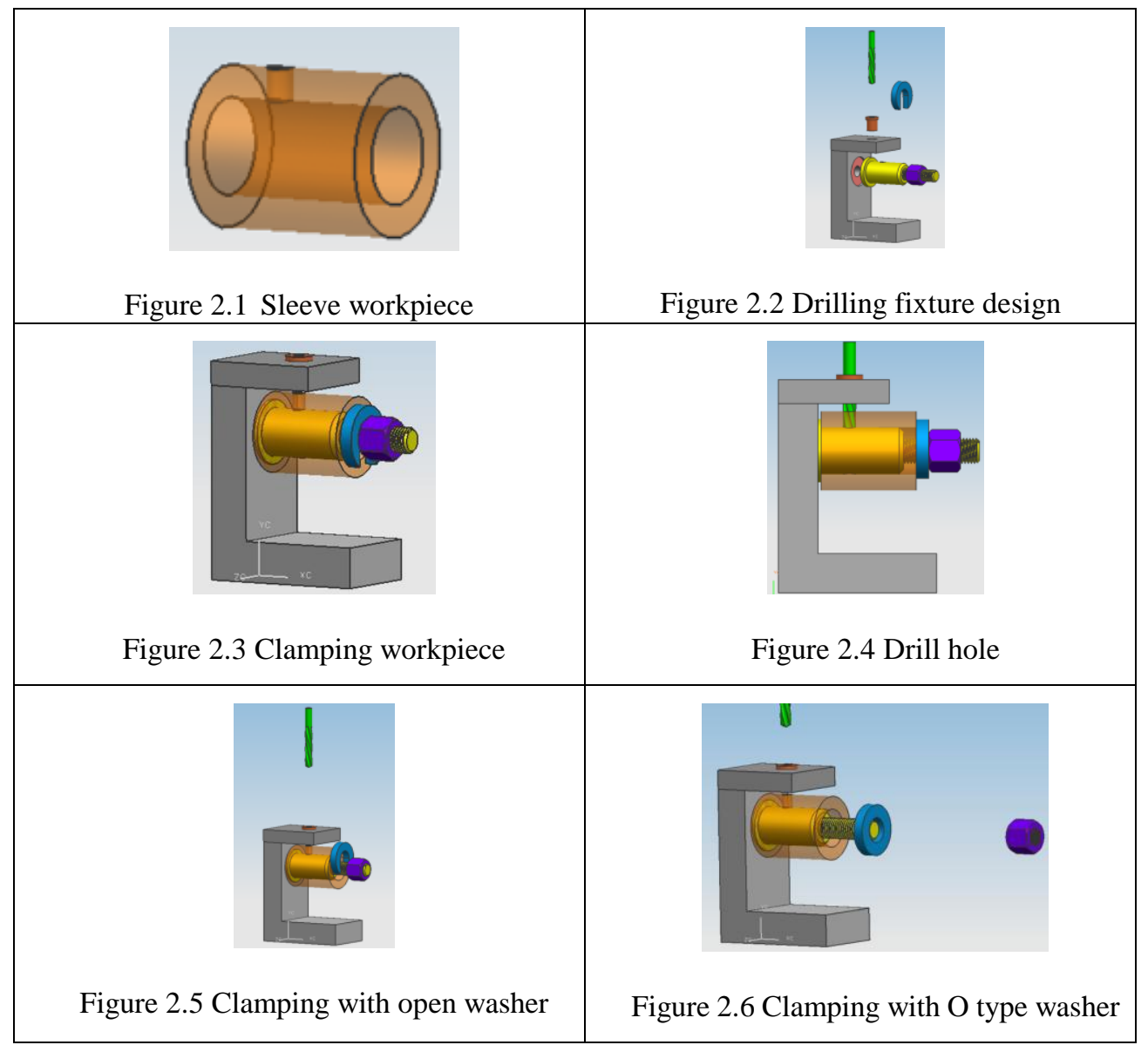

Figure 2 The fixture design of the drilling process of some sleeve part

First, build the model of the part, as shown in figure 2.1. Then design the jig according to processing requirements. Use a small torus and mandrel as the positioning 
element, limiting 5 degree of freedom of the work piece. Use a nut and gasket as clamping mechanism. Use a fixed jig to guide the drill. Model and assemble the components of the fixture, as shown in figure 2.2. Install and clamp the work piece, as shown in Figure 2.3. Drill hole, as shown in Figure 2.4. Withdraw the tool and unload the work piece. Thus a work piece drilling process is finished. VM technology can also be used to compare the details of different clamping devices. For example, the installation efficiency is higher of using open washer than $\mathrm{O}$ type washer, as shown in Figure 2.5 and Figure 2.6. It is known that CAE can also be used to optimize the structure and virtual simulation of the clamping device, and CAM can be used to virtual machining and generating NC code.

\section{Summary}

It is an innovative attempt to reform the teaching methods and contents of the traditional theoretical courses to apply the VM technology in the course teaching of the fundamentals of manufacturing technology. Practice has proved that this teaching reform makes teaching methods more flexible, teaching demonstration more intuitive and teaching effect more obvious, which has a certain reference and promotion significance.

\section{Acknowledgement}

This paper was financially supported by the excellent course project of "fundamental of manufacturing technology" in Guangdong province.

\section{References}

[1] S.L.Zhang, Y.H.Hu, Discussion on the teaching innovation of the course of "mechanical manufacturing technology" in Independent College, Education Exploration, 21(2011).

[2] W.S.Wan.Virtual Manufacturing Technology towards 21st Century. Mechatronics. 2(2004) 11-14.

[3] W.Q.Gao, Q.S.Yan, Z.Qin. Practice and Research in Teaching the Integrated Training of CAD/CAM/CAE Course, Journal of Guangdong University of Technology, Vol.4 Suppl(2004) 182-184.

[4] H.J.Sun, Analysis of the combination of computer aided technology and mechanical design and manufacture, Private technology,3(2016)84.

[5] L.Wang, E.G.Zhang, Discussion of teaching reform of fundamentals of manufacturing technology in Independent Colleges, Examination weekly, 15(2015) 11-12. 